\title{
Reference limits for chromogranin A, CYFRA 21-1, CA 125, CA 19-9 and carcinoembryonic antigen in patients with chronic kidney disease
}

\author{
Gustav Mikkelsen ${ }^{1,2}$, Arne Åsberg ${ }^{1}$, Maria E. Hultström³ ${ }^{3}$ Knut Aasarød²,3, Gunhild G. Hov ${ }^{1,2}$ \\ ${ }^{1}$ Department of Clinical Chemistry, Trondheim University Hospital, Trondheim - Norway \\ ${ }^{2}$ Norwegian University of Science and Technology, Trondheim - Norway \\ ${ }^{3}$ Department of Nephrology, Trondheim University Hospital, Trondheim - Norway
}

\begin{abstract}
Background: Patients with chronic kidney disease (CKD) may have increased plasma concentrations of some tumor markers even when no cancer is present. Previous studies have indicated that plasma concentrations of chromogranin A (CGA), cytokeratin 19 fragments (CYFRA 21-1), cancer antigen 125 (CA 125), cancer antigen 19-9 (CA 19-9) and carcinoembryonic antigen (CEA) are higher in patients with CKD but without cancer, than in healthy individuals, and this can make interpretation of results more complicated. The aim of this study was to establish reference limits for these markers in patients with CKD not receiving dialysis and with no clinical evidence of cancer. Methods: We measured plasma concentrations in samples from 131 patients with CKD due to various etiologies and studied the association of tumor marker concentrations with estimated glomerular filtration rate (GFR) and other patient characteristics.

Results: Estimated reference limits for plasma CA 125, CA 19-9 and CEA were approximately the same as for healthy populations. Serum concentrations of CGA and CYFRA 21-1 correlated strongly with estimated GFR, and GFR-dependent reference limits were estimated.

Conclusions: GFR-dependent reference limits for CGA and CYFRA 21-1 are reported in order to support interpretation of these markers in patients with CKD.
\end{abstract}

Keywords: Chronic renal insufficiency, Glomerular filtration rates, Reference range, Tumor biomarkers

\section{Introduction}

A number of nonmalignant conditions may influence plasma concentrations of tumor markers due to increased release into the blood stream or impaired elimination (1). Molecules eliminated by renal filtration may be retained in the blood in patients with kidney failure. Particularly, this is the case for small molecules with molecular weight below 25-30 kilodaltons ( $\mathrm{kDa}$ ) (2). Correspondingly, plasma concentrations of small-molecularsize tumor markers may increase with decreasing glomerular filtration rate (GFR). In addition, metabolic disturbances in patients with chronic kidney disease (CKD) may influence tumor marker metabolism. If concentrations of tumor markers are

Received: January 26, 2017

Accepted: May 3, 2017

Published online: May 27, 2017

Corresponding author:

Dr. Gustav Mikkelsen

Department of Clinical Chemistry

Trondheim University Hospital

7006 Trondheim, Norway

gustav.mikkelsen@stolav.no; cc: gustav.mikkelsen@ntnu.no significantly altered in patients with CKD for one of these reasons, then interpretation of tumor marker measurements may become more complicated, both with respect to assessing the probability of having a specific malignant disease and whether already diagnosed cancer has progressed or regressed.

Cancer and CKD both affect a large number of people $(3,4)$. Issues related to use of tumor markers in patients with CKD are therefore highly relevant (5). This study aimed to estimate reference limits for some frequently used tumor markers in patients with CKD and impaired GFR, to support a more adequate interpretation of these markers.

\section{Methods}

\section{Patients and samples}

The study population has been described elsewhere (6). Briefly, it comprised 160 nondialysis patients with CKD visiting the renal outpatient clinic in a tertiary hospital between 2007 and 2009. Clinical information was collected from medical records. Serum and plasma samples were collected consecutively as patients were included in the study. All samples were collected during daytime as part of routine care using Vacuette ${ }^{\circledR}$ SST and Lithium Heparin tubes (Greiner-Bio One). 
Patients were not required to be fasting. Samples were stored in sealed $500-\mu \mathrm{L}$ cryotubes at $-80^{\circ} \mathrm{C}$ until analysis of plasma carcinoembryonic antigen (CEA), cancer antigen 19-9 (CA 19-9) and cancer antigen 125 (CA 125) in 2009 and of serum chromogranin A (CGA) and cytokeratin 19 fragments (CYFRA 21-1) in 2015.

\section{Ethics}

The study was approved by the Regional Committee for Medical Research Ethics, and all participants gave informed consent for participation in the study.

\section{Laboratory methods}

All measurements were made according to the manufacturer's instructions with kits from Roche Diagnostics GmbH (Mannheim, Germany), except for CGA for which kits were obtained from Euro Diagnostica AB (Malmö, Sweden), as detailed in Supplementary Table I (available online at www.biological-markers.com - Specifications for analytical methods for tumor markers). Creatinine was measured with an enzymatic method traceable to isotope dilution mass spectrometry and sodium with indirect potentiometry. Estimated glomerular filtration rate (eGFR) was calculated using the Chronic Kidney Disease Epidemiology Collaboration (CKD-EPI) equation (7). Patients were classified into CKD grades 1 to 5 according to whether eGFR was $\geq 90,60-89$, $30-59,15-29$ or $<15 \mathrm{~mL} / \mathrm{min}$ per $1.73 \mathrm{~m}^{2}$, respectively (8). Not all analytes were measured in all samples due to limited sample availability. The analytical quality of all methods was assessed on the basis of internal and external quality assessment programs and found acceptable. The integrity of stored samples was evaluated by comparing concentrations of sodium measured at times of sample collection and tumor marker measurement. In addition, 60 plasma samples from blood donors collected in 2011 were compared with 60 samples from age- and sex-matched blood donors collected in 2016 in order to confirm stability of CYFRA 21-1 and CGA when stored at $-80^{\circ} \mathrm{C}$ for several years.

\section{Statistical analysis}

We used MedCalc Statistical Software v. 15.8 (MedCalc Software bvba, Ostend, Belgium) to estimate reference limits with the robust method as recommended for small sample sizes by the Clinical and Laboratory Standards Institute (9). When appropriate, reference values were partitioned according to CKD grades. Outliers identified with Reed's method (10) were removed. For all other statistical analyses we used SAS v. 9.4 (SAS Institute Inc., Cary, NC, USA). We used Spearman's rank correlation analysis, and the Mann-Whitney-Wilcoxon test to compare tumor marker concentrations between groups. We used quantile regression analysis (11) to investigate relationships between quantiles of tumor marker concentrations and relevant covariates. Quantile regression can be used to estimate any conditional quantile of a continuous variable on 1 or more explanatory variables. It is a nonparametric method and therefore has fewer assumptions regarding the underlying distribution of values than ordinary least squares regression methods. As low concentrations of the tumor markers are of little clinical relevance, only upper reference limits were estimated. Due to the limited number of observations, the reported quantiles were partly chosen to obtain reasonably narrow confidence intervals $(\mathrm{Cl})$. A p value $<0.05$ was considered statistically significant.

\section{Results}

\section{Patient characteristics}

Samples were available from 157 patients, of whom 19 were excluded due to previous or evident cancer at inclusion, or death from cancer before latest record review in 2012. In addition, 7 patients were excluded on suspicion of relevant comorbidity based on results of routine laboratory tests (cardiac troponin $\mathrm{T}=765 \mathrm{ng} / \mathrm{L}$, alanine aminotransferase $=$ $223 \mathrm{U} / \mathrm{L}$, vitamin $\mathrm{B}_{12}=1,298 \mathrm{pmol} / \mathrm{L}, \mathrm{C}$-reactive protein $=65$ and $148 \mathrm{mg} / \mathrm{L}, \mathrm{CA} 19-9=358 \mathrm{kIU} / \mathrm{L}$ and CA $125=155 \mathrm{kIU} / \mathrm{L}$, respectively), leaving 131 patients. Median age was 55 years (range 18 to 85 years). All except 3 patients were white. Median eGFR was $39 \mathrm{~mL} / \mathrm{min}$ per $1.73 \mathrm{~m}^{2}$ (range 12-133). Number of patients with CKD grades 1 to 5 was $17,22,52,33$ and 7, respectively. Table I lists the number of patients with respective clinical kidney disorders.

\section{Sample integrity}

Sodium was measured in patient samples at the time of collection and in samples analyzed in 2015. Median relative difference in sodium concentration between samples from the same patient was $2.2 \%$. The difference was less than $3 \%$ for $75 \%$ and less than $5 \%$ for all 131 patients. If the apparent change in sodium concentration was caused by evaporation of water during storage, median increase in tumor markers due to water loss would be in the order of $2 \%$, which we considered to be negligible with respect to the validity of estimated reference limits. Mean differences (95\% confidence interval $[95 \% \mathrm{CI}]$ ) between samples from blood donors stored at $-80^{\circ} \mathrm{C}$ since 2011 and samples stored for a few weeks were $0.00 \mu \mathrm{g} / \mathrm{L}(95 \% \mathrm{Cl},-0.17$ to 0.17$)$ for CYFRA $21-1$ and $0.14 \mathrm{nmol} / \mathrm{L}(95 \% \mathrm{Cl},-0.18$ to 0.45$)$ for $\mathrm{CGA}$, which is considered to be insignificant.

\section{Chromogranin A}

Seven patients using proton pump inhibitors were excluded, leaving 124 patients for the evaluation of CGA (Fig. 1). CGA correlated inversely with eGFR $(r=-0.83, p<0.001)$. A quantile regression model was fitted for the $90^{\text {th }}$ and $95^{\text {th }}$ percentiles of CGA with inverse eGFR as predictor (Tab. II). Coefficients for age and sex were not statistically significant for any of the percentiles $(p>0.14)$.

Reference limits for CKD grades 3 and 4 , the only subgroups with more than 30 patients, were estimated with the robust method after removal of 1 outlier. For patients with CKD grade 3 , the $90^{\text {th }}$ and $95^{\text {th }}$ percentile reference limits were $10.8(95 \%$ $\mathrm{Cl}, 9.1-12.4)$ and $12.2 \mathrm{nmol} / \mathrm{L}(95 \% \mathrm{Cl}, 10.0-14.1)$, respectively. Corresponding limits for CKD grade 4 were $26.3(95 \% \mathrm{Cl}$, 17.3$32.2)$ and $30.9 \mathrm{nmol} / \mathrm{L}(95 \% \mathrm{Cl}, 19.4-38.4)$. 
TABLE I - Clinical kidney disorders

\begin{tabular}{|c|c|c|c|c|}
\hline \multirow[t]{2}{*}{ Clinical category } & \multicolumn{3}{|c|}{ Number of patients } & \multirow[t]{2}{*}{ eGFR } \\
\hline & Female & Male & Total & \\
\hline $\begin{array}{l}\text { Systemic inflammatory diseases: granulomatosis with poly- } \\
\text { angiitis, systemic vasculitis, systemic lupus erythematosus }\end{array}$ & 11 & 4 & 15 & $43(31-61)$ \\
\hline $\begin{array}{l}\text { Tubulointerstitial disease: interstitial nephritis, polycystic } \\
\text { kidney disease, chronic pyelonephritis, nephrocalcinosis, sar- } \\
\text { coidosis, postrenal disease }\end{array}$ & 8 & 18 & 26 & $37(26-62)$ \\
\hline Glomerulonephritis & 16 & 40 & 56 & $48(31-84)$ \\
\hline $\begin{array}{l}\text { Nephrosclerotic disease: nephrosclerosis, hypertensive } \\
\text { kidney disease }\end{array}$ & 7 & 19 & 26 & $29(20-39)$ \\
\hline Diabetic disease & 1 & 7 & 8 & $36(26-54)$ \\
\hline Total & 43 & 88 & 131 & $39(25-64)$ \\
\hline
\end{tabular}

The specific disorders listed are those most frequent in each group. Estimated glomerular filtration rate (eGFR) is reported as median (1 $1^{\text {st }}$ and $3^{\text {rd }}$ quartiles) in $\mathrm{mL} / \mathrm{min}$ per $1.73 \mathrm{~m}^{2}$.

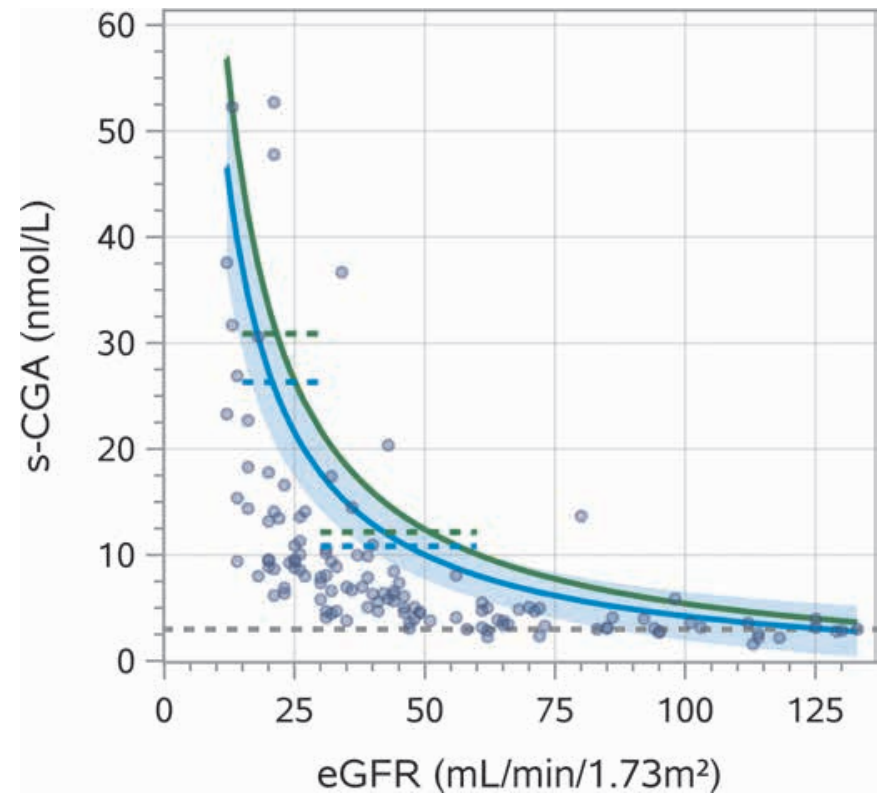

Fig. 1 - Serum concentration of chromogranin A (s-CGA) plotted versus estimated glomerular filtration rate (eGFR). Gray dashed horizontal line corresponds to the $3.0 \mathrm{nmol} / \mathrm{L}$ upper reference limit for CGA (see Supplementary Table I, available online at www. biological-markers.com - Specifications for analytical methods for tumor markers). Blue and green solid lines correspond to quantile regression estimates of the $90^{\text {th }}$ and $95^{\text {th }}$ percentiles, respectively. The blue band represents the $90 \%$ confidence interval for the $90^{\text {th }}$ percentile. Correspondingly, blue and green dashed horizontal lines indicate reference limits estimated with the robust method for chronic kidney disease (CKD) grades 3 and 4 as the $90^{\text {th }}$ and $95^{\text {th }}$ percentiles.

\section{CYFRA 21-1}

CYFRA 21-1 was measured in samples from 131 patients (Fig. 2). CYFRA 21-1 correlated inversely with eGFR ( $r=-0.57$, $\mathrm{p}<0.001$ ). Parameter estimates of a quantile regression model fitted for the $90^{\text {th }}$ and $95^{\text {th }}$ percentiles of CYFRA 21-1 with
TABLE II - Quantile regression parameters for chromogranin A

\begin{tabular}{lcccc}
\hline Percentile & Parameter & Estimate & SE & p value \\
\hline $90^{\text {th }}$ & Intercept & -1.54 & 2.22 & 0.41 \\
& eGFR & & \\
& $95^{\text {th }}$ & 577.53 & 87.53 & $<0.001$ \\
& Intercept & -1.61 & 8.02 & 0.84 \\
& eGFR $^{-1}$ & 700.78 & 288.83 & 0.016 \\
\hline
\end{tabular}

To calculate reference limit values ( $\mathrm{nmol} / \mathrm{L}$ ) for a specific level of estimated glomerular filtration rate (eGFR; $\mathrm{mL} / \mathrm{min}$ per $1.73 \mathrm{~m}^{2}$ ), use the formula: Limit $=\langle$ ntercept $\rangle+\left\langle\mathrm{eGFR}^{-1}\right\rangle \times 1 / \mathrm{eGFR}$, and replace parameters in angle brackets with corresponding parameter estimates in the Table and replace eGFR $_{\text {atient }}$ with the relevant estimated glomerular filtration rate (eGFR). $\mathrm{SE}=$ standard error.

eGFR as predictor are given in Table III. Coefficients for age and sex were not statistically significant $(p>0.15)$.

Based on the distribution of eGFR and the correlation of CYFRA 21-1 with eGFR, separate reference limits for patients with eGFR higher and lower than $60 \mathrm{~mL} / \mathrm{min}$ per $1.73 \mathrm{~m}^{2}$ appeared to be appropriate. In patients with eGFR $\geq 60 \mathrm{~mL} / \mathrm{min}$ per $1.73 \mathrm{~m}^{2}$ (CKD grades 1 and 2), the $90^{\text {th }}$ and $95^{\text {th }}$ percentile reference limits estimated with the robust method were 1.9 $(95 \% \mathrm{Cl}, 1.7-2.1)$ and $2.1 \mu \mathrm{g} / \mathrm{L}(95 \% \mathrm{Cl}, 1.8-2.4)$, respectively. In patients with eGFR $<60 \mathrm{~mL} / \mathrm{min}$ per $1.73 \mathrm{~m}^{2}$ (CKD grades 3 , 4 and 5), the corresponding limits were $3.9(95 \% \mathrm{Cl}, 3.4-4.4)$ and $4.4 \mu \mathrm{g} / \mathrm{L}(95 \% \mathrm{Cl}, 3.8-5.0)$, after removal of 1 outlier.

\section{CA 125}

CA 125 was measured in 127 samples. Fourteen patients using warfarin were excluded on suspicion of having atrial fibrillation (see "Discussion"). There was no statistically significant correlation between CA 125 and eGFR ( $p=0.5)$ or difference between men and women $(p=0.4)$. The $90^{\text {th }}$ and $95^{\text {th }}$ percentile reference limits estimated with the robust method were 27 (95\% Cl, 24-30) and $31 \mathrm{kIU} / \mathrm{L}(95 \% \mathrm{Cl}, 27-35)$, respectively. When only women were included, the corresponding reference limits were $28(95 \% \mathrm{Cl}, 23-34)$ and $32 \mathrm{kIU} / \mathrm{L}(95 \% \mathrm{Cl}$, 


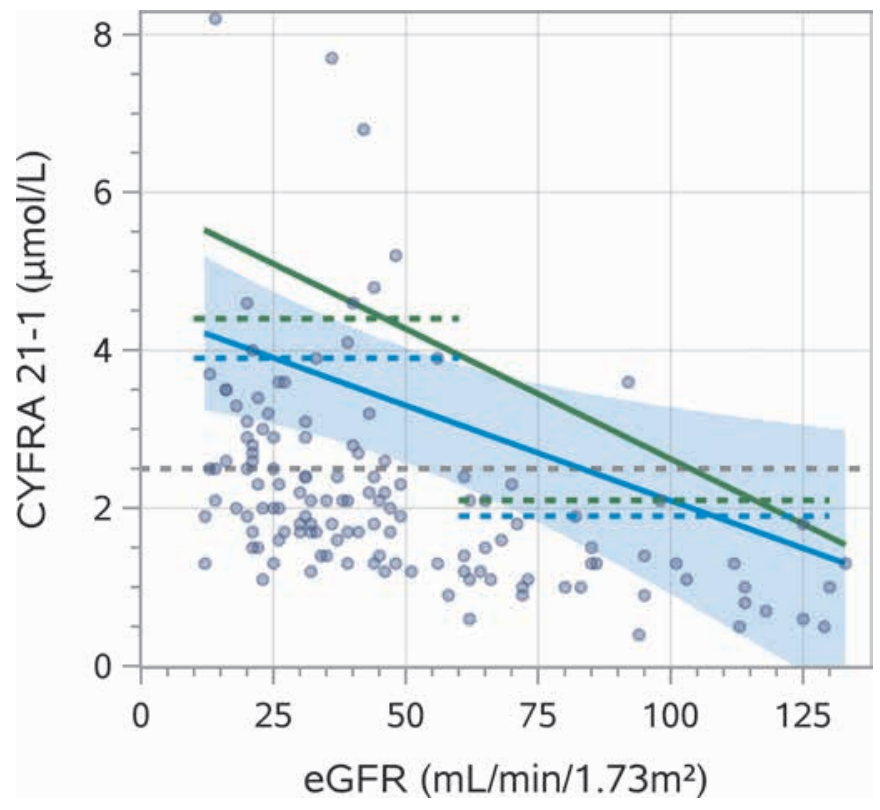

Fig. 2 - Cytokeratin 19 fragments (CYFRA 21-1) plotted versus estimated glomerular filtration rate (eGFR). Gray dashed horizontal line corresponds to the $2.5 \mu \mathrm{g} / \mathrm{L}$ reference limit for CYFRA 21-1 (see Supplementary Table I, available online at www.biological-markers.com - Specifications for analytical methods for tumor markers). Blue and green solid lines correspond to quantile regression estimates of the $90^{\text {th }}$ and $95^{\text {th }}$ percentiles, respectively. The blue band represents the $90 \%$ confidence interval for the $90^{\text {th }}$ percentile. Correspondingly, blue and green dashed horizontal lines indicate the $90^{\text {th }}$ and $95^{\text {th }}$ percentiles estimated with the robust method in patients with eGFR lower or higher than $60 \mathrm{~mL} / \mathrm{min}$ per $1.73 \mathrm{~m}^{2}$.

TABLE III - Quantile regression parameters for CYFRA 21-1

\begin{tabular}{llccr}
\hline Percentile & Parameter & Estimate & SE & p value \\
\hline $90^{\text {th }}$ & Intercept & 4.506 & 0.69 & $<0.01$ \\
& eGFR & -0.024 & 0.01 & 0.03 \\
$95^{\text {th }}$ & Intercept & 5.918 & 1.76 & $<0.01$ \\
& eGFR & -0.033 & 0.03 & 0.30 \\
\hline
\end{tabular}

To calculate reference limit values $(\mu \mathrm{g} / \mathrm{L})$ for a specific level of estimated glomerular filtration rate (eGFR; $\mathrm{mL} / \mathrm{min}$ per $1.73 \mathrm{~m}^{2}$ ), use the formula: Limit = $<$ Intercept $>+<e G F R>\times$ eGFR patient and replace parameters in angle brackets with corresponding parameter estimates in the Table and replace eGFR with the relevant estimated glomerular filtration rate (eGFR).

CYFRA 21-1 = cytokeratin 19 fragments; SE = standard error.

26-39), comparable to the reference limit from the manufacturer's product specifications (35 kIU/L).

\section{CA 19-9}

CA 19-9 was measured in 127 samples. There was no statistically significant difference between men and women $(p=0.3)$ or correlation between CA $19-9$ and eGFR $(p=0.2)$. The $90^{\text {th }}$, $95^{\text {th }}$ and $97.5^{\text {th }}$ percentile reference limits estimated with the robust method were 26 (95\% Cl, 23-29), 30 (95\% Cl, 27-33) and 33 $\mathrm{kIU} / \mathrm{L}(95 \% \mathrm{Cl}, 30-37)$, respectively, which is comparable to the reference limits in the manufacturer's product specifications.

\section{CEA}

CEA was measured in 126 samples. There was no statistically significant difference in CEA between smokers $(n=24)$ and nonsmokers $(p=0.35)$. CEA correlated inversely with eGFR $(r=-0.26, p<0.01)$. Coefficients estimated with quantile regression of the $90^{\text {th }}$ and $95^{\text {th }}$ quantiles of CEA with eGFR, age, sex and smoking status as predictors were not statistically significant. The $95^{\text {th }}$ percentile estimated with the robust method on basis of samples from the 79 nonsmokers aged 40 years or older was $4.4 \mu \mathrm{g} / \mathrm{L}(95 \% \mathrm{Cl}, 3.9-4.8)$ after removal of 1 outlier. The corresponding reference limit from the manufacturer's product specifications is $5.0 \mu \mathrm{g} / \mathrm{L}$. Numbers of patients who were younger than 40 years or smokers were too low to estimate relevant quantiles.

\section{Discussion}

Serum concentrations of CGA and CYFRA 21-1 correlated strongly with eGFR. GFR-dependent upper reference limits may support interpretation of these markers and, if used as diagnostic decision limits, may improve diagnostic specificity compared with regular reference limits, in patients with CKD. Continuous limits estimated by quantile regression have the potential of providing a better fit to the concentrations observed in patients with variable levels of eGFR compared with separate limits - e.g., for different CKD grades.

Chromogranin $A$ is a peptide with a molecular weight of $48 \mathrm{kDa}$. Increased concentration of CGA in plasma is associated with neuroendocrine tumors - e.g., carcinoid tumors, small cell lung cancer, neuroblastoma and pheochromocytoma (12). CGA does not vary with sex and age and does not correlate with blood pressure (13). It may increase in acute coronary syndrome and liver disease (1) and in patients using proton pump inhibitors (14). We therefore excluded patients with suspected influencing factors.

Several studies have demonstrated increased CGA in patients with renal failure (15-17). Our findings agree with Hsiao et al (15), Tramonti et al (16) and Bech et al (17), who observed increasing concentrations of CGA with lower GFR in patients with kidney disease. However, none of these studies reported specific reference limits for CGA at different levels of GFR. Consequently, their results are difficult to apply when trying to decide whether CGA in individual patients with CKD is increased, compared with what is expected according to the patient's GFR. Hsiao et al (15) found no significant effect of sex, age and blood pressure on any central tendency of CGA when adjusted for creatinine. We found no significant additional effect of these variables in a quantile regression model of the $90^{\text {th }}$ and $95^{\text {th }}$ percentiles of CGA.

CYFRA 21-1 antigen identified by the BM 19.21 and KS19.1 antibodies is composed of soluble fragments of cytokeratin 19 with a molecular size of approximately $30 \mathrm{kDa}$. Elevated plasma concentration of CYFRA $21-1$ is associated with epithelial cell carcinomas $(18,19)$, benign pulmonary diseases and liver cirrhosis $(1,20)$. CYFRA $21-1$ does not correlate with age, sex or smoking $(21,22)$.

Our findings are in agreement with several studies demonstrating increased CYFRA 21-1 in patients with renal failure $(19,20,22-25)$. GFR-dependent reference limits were, 
however, not reported in most of these studies. Xiaofang et al (23) reported $90^{\text {th }}$ percentiles for CYFRA 21-1 in Chinese non dialysis CKD patients. As in our study, values increased with decreasing creatinine clearance, but were, in general, almost twice as high as in our study. Likewise, Tong et al (25) measured CYFRA 21-1 in a large number of samples from CKD patients and reported $75^{\text {th }}$ percentiles in patients with CKD grades 1-5 somewhat higher than in our study. As levels of CYFRA 21-1 seem to vary between different healthy populations $(20,25-27)$ we believe that differences with respect to demographic factors, comorbidity or CKD treatment are the most likely explanations for the observed differences between the different CKD populations.

CA 125 is a high-molecular-weight glycoprotein recognized by the monoclonal antibody OC 125 . High plasma concentrations are associated with ovarian carcinoma and malignant diseases in the endometrium, breast and gastrointestinal tract. Nonmalignant causes of increased concentrations are, among others, liver disease, pancreatitis, lung disease, heart failure (1), pleural effusions, ascites $(28,29)$ and pregnancy.

We found approximately the same $95^{\text {th }}$ percentile in patients with CKD as the corresponding reference limit reported in the manufacturer's product specifications, which was based on healthy premenopausal and postmenopausal females. In accordance with this, we observed no significant correlation between CA 125 and eGFR.

Several studies have demonstrated increased CA 125 in patients with renal failure $(23,30-32)$. Filella et al (30) observed increased CA 125 in $17 \%$ of patients with chronic renal failure, but no correlation with creatinine. Xiaofang et al (23) observed increased levels of CA 125 in patients with CKD. In subgroups according to sex and creatinine clearance, they reported $90^{\text {th }}$ percentiles 3-4 times as high as we observed, even though we apparently used the same analysis method. The 2 populations appear not to be comparable, possibly due to differences with respect to comorbidity.

In our study, use of warfarin was strongly associated with high serum concentrations of CA 125 . Although we did not collect specific information regarding the reasons for anticoagulant therapy, some of these patients likely had atrial fibrillation (AF). As AF is associated with heart failure, fluid retention and elevated CA 125 (33), patients with high probability of AF were excluded from the final analysis in our study. It is possible that increased CA 125 observed in some patients with kidney disease is associated more with fluid overload than impaired GFR.

CA 19-9 recognized with the monoclonal antibody 1116NS-19-9 is a high-molecular-weight glycolipid antigen. Increased serum concentrations are associated with pancreatic and gastrointestinal malignancies, but CA 19-9 may also be elevated in other gastrointestinal, hepatobiliary and pulmonary disorders (1).

We found reference limits in patients with CKD comparable to those in a healthy population reported in the manufacturer's product specifications. This is in agreement with Filella et al (30), who did not observe increased frequency of CA 19-9 above cutoff in patients with chronic renal failure. However, Arik et al (32) observed almost twice as high a mean CA 19-9 in predialysis patients with chronic renal failure as in healthy controls. Likewise, Xiaofang et al (23), who apparently used the same method as we did, reported medians and $90^{\text {th }}$ percentiles in groups with different levels of creatinine clearance almost twice as high as in our study. Dissimilarities related to the study populations and possibly the analytical methods may explain these differences (34).

Carcinoembryonic antigen is a high-molecular-weight glycoprotein of approximately $180 \mathrm{kDa}$. Increased serum concentrations are associated with colorectal carcinoma but may also be observed in nonmalignant disorders of the intestine, liver, pancreas and lungs (1). CEA correlates with age and is frequently increased in smokers (35).

We estimated the $95^{\text {th }}$ percentile reference limit of CEA among nonsmoking patients with CKD aged 40 years or older to be somewhat lower than the corresponding limit reported in the manufacturer's product specifications. This is in agreement with Arik et al (32), who observed mean CEA in predialysis patients with chronic renal failure not different from that of healthy controls. In studies by Filella et al (30) and Nomura et al (36), CEA correlated with creatinine, as we also observed in our study. However, they both observed a substantial number of patients with CEA above upper reference limits. As smoking habits were not reported, results are difficult to interpret. Tong et al (25) reported medians and $75^{\text {th }}$ percentiles in patients with CKD grades 1 to 5 approximately as in our study. However, they also did not record information about smoking habits.

\section{Study limitations}

The number of patients included in the present study was limited, therefore the choice of reference limits was done on the basis of which percentiles could be estimated with acceptable precision. Although patients with evident cancer were excluded, we cannot rule out that some patients with undetected cancer were included in our study. As the probability is low and not related to GFR, this is unlikely to have had a significant influence on the estimated reference limits. Samples were stored in $-80^{\circ} \mathrm{C}$ for several years before analysis. As differences in sodium concentrations measured at time of inclusion and in 2015 were small, increased concentrations due to evaporation were probably negligible. Degradation of tumor markers during storage was probably small $(37,38)$ and most likely independent of patient GFR. Hence, we believe this did not have a significant influence on the observed association between eGFR and marker concentrations.

\section{Conclusions}

To support the interpretation of tumor marker measurements in CKD patients, we estimated GFR-dependent reference limits for CGA and CYFRA 21-1 in patients with eGFR ranging from 12 to $133 \mathrm{~mL} / \mathrm{min}$ per $1.73 \mathrm{~m}^{2}$. Reference limits for CA 19-9, CA 125 and CEA were approximately the same as in healthy populations.

\section{Disclosures}

Financial support: Trondheim University Hospital, Trondheim, Norway, supported the study financially.

Conflict of interest: Authors declare they have no conflicts of interest. 


\section{References}

1. Trapé J, Filella X, Alsina-Donadeu M, Juan-Pereira L, BoschFerrer Á, Rigo-Bonnin R. Oncology Section of the Catalan Association of Clinical Laboratory Science. Increased plasma concentrations of tumour markers in the absence of neoplasia. Clin Chem Lab Med. 2011;49(10):1605-1620.

2. Burtis CA, Ashwood ER, Bruns DE, eds. Tietz textbook of clinical chemistry and molecular diagnostics. $5^{\text {th }}$ ed. Saint Louis, MO: Elsevier/Saunders. 2013:1539-1540.

3. Fitzmaurice C, Dicker D, Pain A, et al. Global Burden of Disease Cancer Collaboration. The global burden of cancer 2013. JAMA Oncol. 2015;1(4):505-527.

4. Jha V, Garcia-Garcia G, Iseki K, et al. Chronic kidney disease: global dimension and perspectives. Lancet. 2013;382(9888): 260-272.

5. Lacava V, Coppolino G, Puntorieri E, et al. Nephro-oncology: a link in evolution. Ren Fail. 2015;37(8):1260-1266.

6. Hov GG, Sagen E, Hatlen G, Bigonah A, Åsberg A, Aasarød K. Arginine/asymmetric dimethylarginine ratio and cardiovascular risk factors in patients with predialytic chronic kidney disease. Clin Biochem. 2011;44(8-9):642-646.

7. Levey AS, Stevens LA, Schmid CH, et al. CKD-EPI (Chronic Kidney Disease Epidemiology Collaboration). A new equation to estimate glomerular filtration rate. Ann Intern Med. 2009;150(9):604-612.

8. National Kidney Foundation. K/DOQI clinical practice guidelines for chronic kidney disease: evaluation, classification, and stratification. Am J Kidney Dis. 2002;39(2)(Suppl 1):S1-S266.

9. Clinical and Laboratory Standards Institute. Defining E: verifying reference intervals in the clinical laboratory. Approved Guideline (C28-A3c). $3^{\text {rd }}$ ed. Wayne, PA: Clinical and Laboratory Standards Institute (CLSI). 2008.

10. Reed AH, Henry RJ, Mason WB. Influence of statistical method used on the resulting estimate of normal range. Clin Chem. 1971;17(4):275-284.

11. Koenker R. Quantile regression. New York: Cambridge University Press; 2005.

12. Louthan O. Chromogranin a in physiology and oncology. Folia Biol (Praha). 2011;57(5):173-181.

13. Glinicki $P$, Jeske W. Chromogranin $A(C g A)$ : the influence of various factors in vivo and in vitro, and existing disorders on its concentration in blood. Endokrynol Pol. 2010;61(4): 384-387.

14. Pregun I, Herszényi L, Juhász $M$, et al. Effect of proton-pump inhibitor therapy on serum chromogranin a level. Digestion. 2011;84(1):22-28.

15. Hsiao RJ, Mezger MS, OConnor DT. Chromogranin A in uremia: progressive retention of immunoreactive fragments. Kidney Int. 1990;37(3):955-964.

16. Tramonti G, Ferdeghini M, Annichiarico $C$, et al. Relationship between renal function and blood level of chromogranin $A$. Ren Fail. 2001;23(3-4):449-457.

17. Bech PR, Ramachandran R, Dhillo WS, Martin NM, Bloom SR. Quantifying the effects of renal impairment on plasma concentrations of the neuroendocrine neoplasia biomarkers chromogranin A, chromogranin B, and cocaine- and amphetamine-regulated transcript. Clin Chem. 2012;58(5):941-943.

18. Huang YL, Chen J, Yan W, Zang D, Qin Q, Deng AM. Diagnostic accuracy of cytokeratin-19 fragment (CYFRA 211) for bladder cancer: a systematic review and meta-analysis. Tumour Biol. 2015;36(5):3137-3145.

19. Sarwar M, Tomiyoshi K, Inoue T, Fukazawa K, Endo K. CYFRA 211 as a tumor marker used in measuring the serum fragment of cytokeratin subunit 19 by immunoradiometric assay. Ann Nucl Med. 1994;8(4):301-306.
20. Molina R, Agusti C, Filella X, et al. Study of a new tumor marker, CYFRA 211, in malignant and nonmalignant diseases. Tumour Biol. 1994;15(6):318-325.

21. Ebert W, Drings P. CYFRA 21-1 beim Bronchialkarzinom: Ergebnisse einer prospektiven Multicenterstudie. In: Spanuth $\mathrm{E}$, ed. Malignome und Hämostase, 11. Heidelberger Symposium Neue Entwicklungen in der Hämostaseologie. Berlin: Springer. 1996:107-122.

22. Rastel D, Ramaioli A, Cornillie F, Thirion B. CYFRA 211, a sensitive and specific new tumour marker for squamous cell lung cancer: report of the first European multicentre evaluation. CYFRA 211 Multicentre Study Group. Eur J Cancer. 1994;30A(5):601-606.

23. Xiaofang $Y$, Yue $Z$, Xialian $X$, Zhibin $Y$. Serum tumour markers in patients with chronic kidney disease. Scand J Clin Lab Invest. 2007;67(6):661-667.

24. Tramonti G, Ferdeghini M, Donadio $C$, et al. Renal function and serum concentration of five tumor markers (TATI, SCC, CYFRA 211, TPA, and TPS) in patients without evidence of neoplasia. Cancer Detect Prev. 2000;24(1):86-90.

25. Tong HL, Dong ZN, Wen XY, Gao J, Wang B, Tian YP. Impact of chronic kidney disease on serum tumor markers concentrations. Chin Med J (Engl). 2013;126(2):274-279.

26. Deng $\mathrm{YF}$, Chen $\mathrm{P}$, Lin YZ, et al. Analytical and clinical evaluation of CYFRA 211 by electrochemiluminescent immunoassay in head and neck squamous cell carcinoma. J Laryngol Otol. 2003;117(3):190-194.

27. Xu RH, Liao CZ, Luo Y, et al. Optimal cut-off values for CYFRA 211 expression in NSCLC patients depend on the presence of benign pulmonary diseases. Clin Chim Acta. 2015;440:188-192.

28. Trapé J, Molina R, Sant F. Clinical evaluation of the simultaneous determination of tumor markers in fluid and serum and their ratio in the differential diagnosis of serous effusions. Tumour Biol. 2004;25(5-6):276-281.

29. Bergmann JF, Bidart JM, George M, Beaugrand M, Levy VG, Bohuon C. Elevation of CA 125 in patients with benign and malignant ascites. Cancer. 1987;59(2):213-217.

30. Filella X, Cases A, Molina R, et al. Tumor markers in patients with chronic renal failure. Int J Biol Markers. 1990;5(2):85-88.

31. Eerdekens MW, Nouwen EJ, Pollet DE, Briers TW, De Broe ME. Placental alkaline phosphatase and cancer antigen 125 in sera of patients with benign and malignant diseases. Clin Chem. 1985;31(5):687-690.

32. Arik N, Adam B, Akpolat T, Haşil K, Tabak S. Serum tumour markers in renal failure. Int Urol Nephrol. 1996;28(4):601-604.

33. Durak-Nalbantic A, Resic N, Kulic M, et al. Serum level of tumor marker carbohydrate antigen-CA125 in heart failure. Med Arh. 2013;67(4):241-244.

34. Galli C, Basso D, Plebani M. CA 199: handle with care. Clin Chem Lab Med. 2013;51(7):1369-1383.

35. Bjerner J, Høgetveit A, Wold Akselberg K, et al. Reference intervals for carcinoembryonic antigen (CEA), CA125, MUC1, alfafoeto-protein (AFP), neuron-specific enolase (NSE) and CA19.9 from the NORIP study. Scand J Clin Lab Invest. 2008;68(8): 703-713.

36. Nomura F, Koyama A, Ishijima M, Takano S, Narita M, Nakai T. Serum levels of five tumor markers for lung cancer in patients with chronic renal failure. Oncol Rep. 1998;5(2):389-392.

37. Christenson RH, Cervelli DR, Sterner J, et al. Analytical performance and clinical concordance of the cancer biomarkers CA 153, CA 199, CA 125 II, carcinoembryonic antigen, and alphafetoprotein on the Dimension Vista ${ }^{\circledR}$ system. Clin Biochem. 2011;44(13):1128-1136.

38. Kugler KG, Hackl WO, Mueller LA, Fiegl H, Graber A, Pfeiffer RM. The impact of sample storage time on estimates of association in biomarker discovery studies. J Clin Bioinforma. 2011;1(1):9. 